\title{
Influence of Surface Treatment on the Strength of Adhesive Joints
}

\author{
Elżbieta Doluk ${ }^{1}$ (0000-0003-2605-1394), Anna Rudawska ${ }^{1}$ (0000-0003-3592-8047), Dana Stančeková2 (0000-0003- \\ 0713-8750), Jozef Mrázik² (0000-0002-1793-6185) \\ ${ }^{1}$ Lublin University of Technology, Faculty of Mechanical Engineering, Lublin, Poland, E-mail: e.doluk@pollub.pl, \\ a.rudawska@pollub.pl \\ ${ }^{2}$ University of Zilina, Faculty of Mechanical Engineering, Zilina, Slovakia, E-mail: \\ dana.stancekova@fstroj.uniza.sk,jozef.mrazik@fstroj.uniza.sk
}

The article compared the strength results of the single-lap adhesive joints made of galvanized steel sheet. The shear strength of the adhesive joints was determined for two methods of surface treatment - using a degreaser $(\operatorname{method} B)$ and without a degreaser $(\operatorname{method} A)$. A two-component epoxy adhesive based on Bisphenol A was used for joining. The shear strength tests were carried out on a Zwick/Roell Z150 testing machine. The analysis of the surface roughness parameters of the samples for the method A was performed. The highest shear strength value $(8.82 \mathrm{MPa})$ was obtained by method $\mathrm{B}$ and using P120 abrasive paper. The lowest shear strength value (4.08 MPa) was received using method A and P600 abrasive paper. The maximum values of measured surface roughness parameters were recorded for samples prepared with abrasive papers with granulations, respectively: P120, P220 and P180. The lowest values of Ra, Rz and Rt parameters gained using P600 abrasive paper.

Keywords: adhesive joints, shear strength, adhesive composition, degreasing, roughening

\section{Introduction}

With the rapid progress in the field of materials engineering and the emergence of modern adhesives, an increase in interest in bonding technology can be observed. The growing interest in using this type of connections is also associated with the advantages of the process, like: the possibility of combining different construction materials, lack of stress concentration or reduction of the mass of the structure [1,2]. In addition, these joints are characterized by corrosion resistance, ability to damp vibrations and have sealing properties. On the other hand, adhesive joints are usually not resistant to changing environmental factors (especially to temperature fluctuations). Moreover, bonding is more time-consuming process compared to other ways of joining materials [3-5].

The bonding process can be carried out using various methods, means and operations. The selection of appropriate conditions depends on many factors, which include, first and foremost, the type of materials to be joined, and the type and form of the adhesive. Typical bonding operations include surface treatment, adhesive preparation andapplication, fixing and assembling elements, adhesive curing, control and secondary operations [5-7].

Creating the adhesive properties of the adhesive joints, it mainly comes down to proper surface preparation, improving the surface layer using physical and chemical methods and making the joint. The strength of the adhesive joint is closely related to the correctness of surface treatment, so it is so important to pay special attention to this stage of bonding process. A properly prepared surface treatment process determines the connection with the desired properties [810].

The process of surface treatment includes degreasing, cleaning in an acid or alkaline bath, rinsing in water, mechanical treatment, drying and secondary operations. This process involves removing grease, dust, deposits, oils, microorganisms and moisture from the surface of the samples. The use of coated abrasive tools is one of the simpler and generally available options for surface treatment of materials before bonding. Abrasive coating tools are the most convenient tools for treatment of surface materials intended for bonding and sealing. This is mainly due to its low cost, availability, ease of use in manual operations, and the possibility of using it in many different conditions. Also important is the ease of obtaining a non-directional structure of the processing marks, which is advantageous, especially in the conditions of structural bonding. When selecting abrasive coated tools for machining, the grain size is an important issue. A grinding abrasive tool with a larger grain removes the material layer more efficiently, including the physicsorption layer, but the degree of development is lower. Smaller grain develops the surface to a greater extent, but too small grain reduces the effectiveness of the adsorption layer removal. The applied mechanical treatment was primarily aimed at increasing the geometric surface of the bond by roughening it. The formation of unevenness contributes to better penetration of the adhesive 
into micropores and surface irregularities, and the creation of mechanical anchors after the adhesive has cured. Of course, it depends on the wettability of the surface by the adhesive, taking into account the energy state of the surface. In the case of rough surfaces, the mechanical adhesion is increased, so that stronger adhesive bonds can be obtained. Different grain size of coated abrasive tools may constitute different surface roughness and adhesive wetting conditions.

Proper surface preparation in the bonding process increases the resistance of the joint to external factors and determines the correct operation of the joint $[4,8]$. The process of surface treatment depends on technical conditions, properties of adhreneds and workshop possibilities. Obtaining the right adhesive joint requires consideration of material, technological, constructional and related factors with joining operation $[11,12]$. The strength of adhesive joints depends on the properties of the adhesive, the type of materials to be joined, the dimensions of the adhesive joint, type and load value, curing time and loading, temperature, mechanical properties of the adhesive and physical properties of the adhreneds [13-17]. The surface treatment process of galvanized steel sheets usually includes degreasing, etching, rinsing and drying operations. The galvanized surfaces can also be treated with phosphating, chromating and coating of polymer materials $[14,18,19]$.

The surface treatment of galvanized steel sheets intended for bonding should be carried out immediately before the start of the process [20]. The results presented in [21] indicated that, based on the SEM photographs obtained for both hot-dip galvanized sheets (such sheets were analyzed in this article but a different type of hot-dip zinc coated sheets) and electrolytically, it can be stated that the treatment with abrasive tools and under certain conditions does not affect the continuity of the zinc coating. In this work for machining, abrasive coated tools of grain P120, P320 and P500 were used.

Shang et al. [22] tested the influence of the structural factors on the composite adhesive joints. They described the several techniques to increasing the transverse strength of the composite adherends. In [23] the effect of the surface roughness parameters and the adhesive properties on the single-lap aluminium joint was examined. It was stated that the tested factors affect the joint resistance. However, there was no interaction between the resin and substrate surface condition. In [24] the influence of geometry, surface treatment, environment, material and geometry was considered. It has been noticed that the main factor influencing the strength of the adhesive joints was the overlap length.

The issue considered in the following work is to examine the effect of surface treatment on the adhe- sive joint of steel sheets with hot dip galvanized coating.

\section{Materials and Methods}

\subsection{Adhesive joint characteristics}

A single-lap adhesive joint made of hot-dip zinc coated steel sheets (1.0035 structural steel) (PN-EN 10025:2002) was used in this study. The material used was DX51D + Z275 sheet - the weight of the zinc coating is $275 \mathrm{~g} / \mathrm{m}^{2}$ (PN-EN 10346). The thickness of the coating is $18 \mu \mathrm{m}$. The geometry and dimensions of the adherend are shown in Fig. 1.

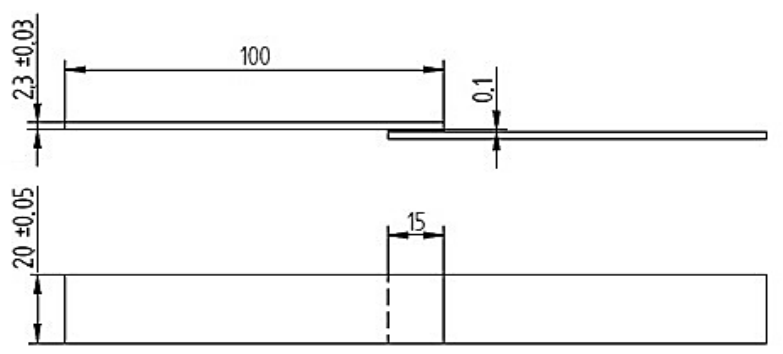

Fig. 1 Geometry and dimensions of the sample

The dimensions of the adhesive joints samples after the bonding process (after curing) were as follows:

- $100 \mathrm{~mm}$ - length of the adherends,

- $15 \pm 2.55 \mathrm{~mm}$ - length of the lap,

- $2.3 \pm 0.03 \mathrm{~mm}$ - thickness of the adherends,

- $20 \pm 0.05 \mathrm{~mm}$ - width of the adherends,

- $0.1 \pm 0.05 \mathrm{~mm}$ - thickness of the adhesive layer.

\subsection{Surface treatment}

Before making the adhesive joint, the jointed surfaces were machined using abrasive papers with P120, P180, P220, P400 and P600 granularity. Half of the samples were additionally degreased with the use of cleaning cloth impregnated with extractor solvent (PIKKO, Dragon Poland) used ad degreasing agent, left for a few seconds on the surface of the adherends until evaporation (method B) (about two minutes). The remaining part of the samples was joined without prior use of the degreaser (method A). The study was performed using two input factors: method of degreasing $\mathrm{M}$ (two levels) and granularity of abrasive paper P (five levels) (Table 1).

\section{Tab. 1 The design of the experiment}

\begin{tabular}{|c|c|c|c|c|c|}
\hline Factors & \multicolumn{5}{|c|}{ Levels } \\
\hline M: method & \multicolumn{5}{|c|}{ A - without a degreaser } \\
\hline $\begin{array}{l}\text { P: granulation of } \\
\text { abrasive paper }\end{array}$ & 120 & 180 & 220 & 400 & 600 \\
\hline M: method & \multicolumn{5}{|c|}{$B$ - with a degreaser } \\
\hline $\begin{array}{l}\text { P: granulationof } \\
\text { abrasive paper }\end{array}$ & 120 & 180 & 220 & 400 & 600 \\
\hline
\end{tabular}


The process of surface treatment of hot dip galvanized steel sheets samples was carried out at $26^{\circ} \mathrm{C} \pm$ $2{ }^{\circ} \mathrm{C}$ with an air humidity of $23 \% \pm 3 \%$.

\subsection{Adhesive and adhesive joint formation conditions}

The two-component epoxy adhesive based on Bisphenol A was used to preparing adhesive joints. The epoxy resin (Eidian 53, trade name, CIECH Resins, Nowa Sarzyna, Poland) is a styrene-modified epoxy resinwith an epoxy number of 0.41 (mol/100 g). The amine curing agent (triethylenetetramine curing agent, Z-1 trade name, CIECH Resins, Nowa Sarzyna, Poland) with an amine number of $1100 \mathrm{mg}$ $\mathrm{KOH} / \mathrm{g}$ was also used. The amount of the resin and the curing agent was used within and above the recommended stoichiometric ratio. The quantitative ratio of the elements (stoichiometric ratio) in a chemical compound by mass was used in the study. The range of this ratio is 10 amount of this curing agent per 100 $\mathrm{g}$ of this epoxy resin.

The components of the epoxy adhesive were dosed using an electronic scale (OX-8100, mfg. FAWAG S.A, Poland, measurement accuracy $0.1 \mathrm{~g}$, ISO 9001) in a polymer-plastic container, taking into consideration the appropriate weight proportions. The components of epoxy adhesive were mixed mechanically at a mixing station with the use of a horseshoe mixer. The components were mixed at a speed of $460 \mathrm{rpm}$ for 2 minutes. During mixing the components, care was taken to prevent air bubbles from forming in the epoxy compound mass. The epoxy compound was then subjected to a degassing process (for about 2 minutes) at the special station equipped with a container and a vacuum pump. The components were mixed in a weight ratio of 100:10 to give an epoxy adhesive Epidian 53/Z-1/100:10.

Immediately after the glue was prepared, the joints were made. The Epidian 53/Z-1/100:10 Epoxy adhesive was applied with a uniform, thin layer (about 0.1 $\mathrm{mm}$ ) on both surfaces to be joined. The samples were cured for 14 days under a load of $0.18 \mathrm{MPa}$. The adhesive joints were made in packets of 6 adhesive joints.

Table 2 presents the number of samples used in the experiment for two methods depending on the type of abrasive paper used.

Tab. 2 The number of samples tested in the experiment

\begin{tabular}{ccc}
\hline $\begin{array}{c}\text { Granulation of } \\
\text { abrasive paper }\end{array}$ & $\begin{array}{c}\text { Method of surface treatment } \\
\text { Method A } \\
\text { (pcs) }\end{array}$ & $\begin{array}{c}\text { Method B } \\
\text { (pcs) }\end{array}$ \\
\hline P120 & 12 & 12 \\
P180 & 12 & 12 \\
P220 & 12 & 12 \\
P400 & 12 & 12 \\
P600 & 12 & 12 \\
\hline TOTAL & 60 & 60 \\
\hline
\end{tabular}

Two batches of the adhesive joints specimens (Method A and Method B) for five variants of surface treatment (Table 1) were fabricated. Each batch comprised 60 adhesive joints specimens and the total number of adhesive joints samples was 120 .

The bonding process was carried out at $26^{\circ} \mathrm{C} \pm 2{ }^{\circ} \mathrm{C}$ with an air humidity of $23 \% \pm 3 \%$.

\subsection{Tests}

The shear strength tests were carried out on a Zwick/Roell Z150 testing machine in accordance with the PN-EN 1465 standard. The test speed was 5 $\mathrm{mm} / \mathrm{min}$.

The Hommel TESTER 1000 profilometer was used to assess the geometric structure of the sample surfaces. Surface roughness tests were carried out for 3 samples for each type of abrasive paper for method A (without using a degreaser). The selected surface roughness parameters were measured $(\mathrm{Ra}, \mathrm{Rz}, \mathrm{Rt}) \mathrm{ac}-$ cording to PN-EN ISO 4287 AMD 12010.

\section{Results}

\subsection{Shear strength results}

The strength results of the adhesive joints for both methods of treatment are shown in Fig. 2.

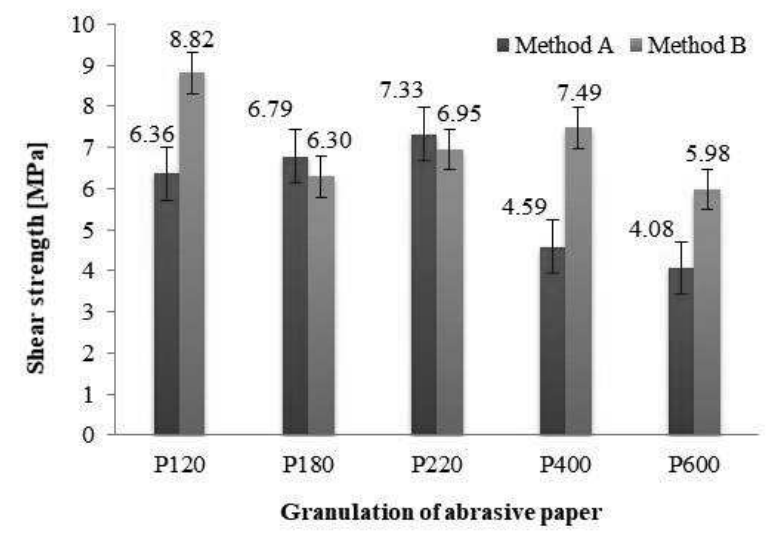

Fig. 2 Comparison of the joint strength results for the surface treatment methods

Examining the above results, it can be stated that the highest shear strength value $(8.82 \mathrm{MPa})$ was received for samples prepared by method B using P120 abrasive paper and the lowest (4.08 MPa) for samples prepared by method A and using P600 abrasive paper. The difference between the maximum values obtained by methods $\mathrm{A}$ and $\mathrm{B}$ was nearly $17 \%$. The minimum value of shear strength result obtained using method $\mathrm{B}$ was about $32 \%$ higher than the analogous value gained by method $\mathrm{A}$.

The influence of the main factors and their interactions on the shear strength of the adhesive joints was analyzed by two-factors ANOVA. The aim of ANOVA is to investigate the effect of two classifying factors (divided into many levels) on the values of the depended variable. 
Tab. 3 ANOV A for the shear strength

\begin{tabular}{lccccc}
\hline Source & Sum of Squares & df & Mean Square & F-Ratio & p-Value \\
\hline M: method & 21.88 & 1 & 21.88 & 18.78 & $<0.01$ \\
P: granulation of abrasive pa- & 48.82 & 4 & 12.21 & 10.48 & $<0.01$ \\
per & 29.17 & 4 & 7.29 & 6.26 & $<0.01$ \\
Interaction PxM & 47.76 & 41 & 1.17 & & \\
Total error & 147.63 & 50 & & & \\
Total (corrected) & & & &
\end{tabular}

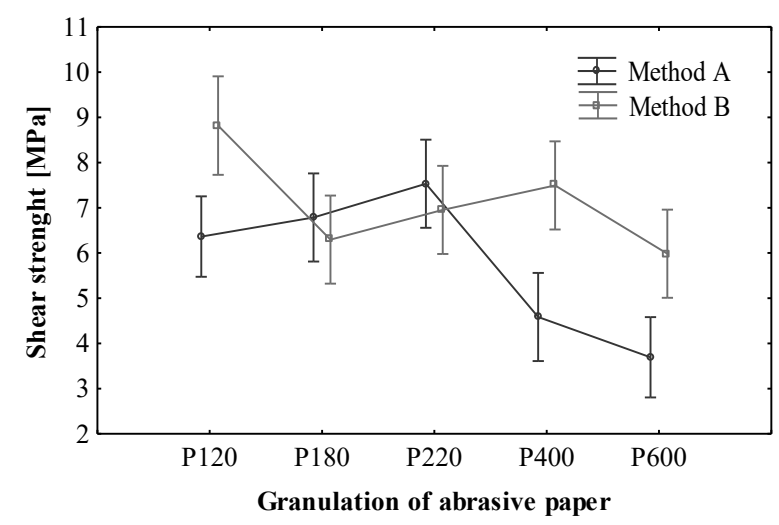

Fig 3 Graphical interpretation of the post hoc Tukey's test

Based on the above results, it was found that all factors have $\mathrm{p}$-values less than 0.05 . The results are statistically significant at the $95 \%$ confidence interval. The highest effect on the shear strength of the adhesive joints (the highest F-ratio) has the method of the surface treatment $(\mathrm{M})$, followed by the granulation of the abrasive paper $(\mathrm{P})$ and interaction $\mathrm{P} \times \mathrm{M}$ (Table 3). The Tukey's post hoc test was performed to extract means that were not statistically different. (Fig. 3).

The graphical interpretation of the Turkey's test shows the average strength values and confidence intervals (vertical bars). The occurrence of statistically significant differences between the factors is represented by the overlapping of the bars. The statistically significant interaction effect is illustrated by the intersection of the line plots. If the confidence intervals do not overlap and the interaction charts are parallel, the factors do not differ statistically significantly.

Analysing Fig. 3 it can be noticed that the results were divided into four homogeneous groups. For P180 and P220 abrasive papers there are no statistically significant differences. The remaining results differ statistically. The statistically significant interaction effect occurred between the two groups of factors.

Tab. 4 Correlations of the shear strength and surface treatment

\section{Correlation:}

shear strength vs

$$
\text { Mean Standard deviation }
$$

r $\quad r^{2}$

p-Value

\begin{tabular}{|c|c|c|c|c|c|}
\hline M: method & 36.00 & 46.41 & -0.059 & 0.004 & 0.679 \\
\hline $\begin{array}{l}\text { P: granulation of abrasive } \\
\text { paper }\end{array}$ & 36.00 & 46.41 & -0.057 & 0.003 & 0.692 \\
\hline
\end{tabular}

The effect of the surface treatment (method of degreasing and granulation of abrasive paper) on the strength of the adhesive joint was made based on the Pearson linear correlation coefficient $r$ using the Statistica program (Table 3). It was stated that the value of this coefficient for both factors was about $-0,06$, which proves a weak correlation between the analysed variables.

\subsection{Surface roughness results}

The surface roughness parameters were tested for 3 samples with each type of the abrasive papers. The surface roughness was measured only for samples prepared without using a thinner (method A). Fig. 4 shows the shaping of selected roughness parameters depending on the granularity of the abrasive paper.

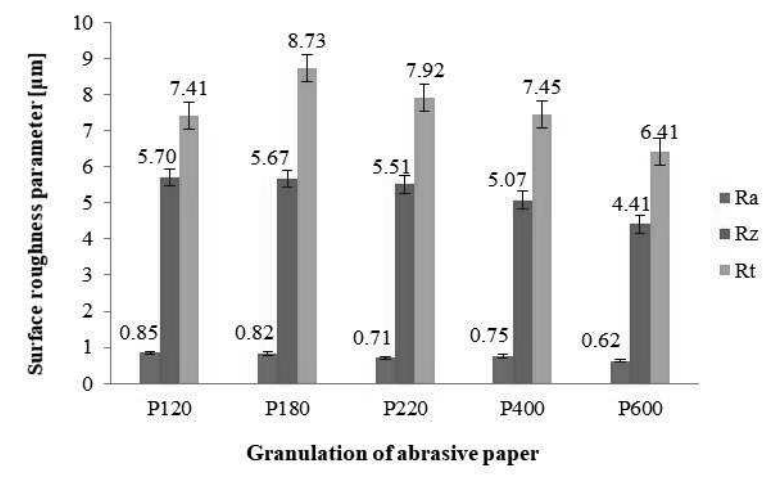

Fig. 4 Surface roughness for the samples prepared by method A 
Based on the above Figure, it was stated that the highest average values of $R$ a surface roughness parameter $(0.85 \mu \mathrm{m})$ was obtained using P120 abrasive paper and the lowest $(0.67 \mu \mathrm{m})$ for the samples prepared with P600 abrasive paper. The difference between the extremes of this parameter was nearly $21 \%$. For the $\mathrm{Rz}$ surface roughness parameter, the maximum value $(5.70 \mu \mathrm{m})$ was achieved during machining with P120 abrasive paper and the lowest $(4.41 \mu \mathrm{m})$ for the samples prepared with $\mathrm{P} 600$ abrasive paper. The maximum value was about $23 \%$ higher than the minimum value. The highest value $(8.73 \mu \mathrm{m})$ of Rt surface roughness parameter was perceived using P180 abrasive paper and the lowest $(6.41 \mu \mathrm{m})$ for P600 abrasive paper. The difference between the extremes of Rt parameter was about $27 \%$.

\section{Discussion}

The effects of the surface treatment on the shear strength of the adhesive joint were stated. The two input factors were examined: method on two levels and granulation of abrasive paper on five levels. On the basis of the obtained results, it was observed that the shear strength was depended on the surface treatment. The similar contained in [25].

The visual analysis of the failure of adhesive joints was made based on PN-EN ISO 10365 standard. Examining the failure results of the tested adhesive joints, according to PN-EN ISO 10365 standard, it can be stated that the most frequent type of failure was adhesion failure (AF) - in about $80 \%$ of the assessed adhesive joints - Fig. 5. However sometimes, special cohesion failure (SCF) or cohesion failure (CF) was also observed.

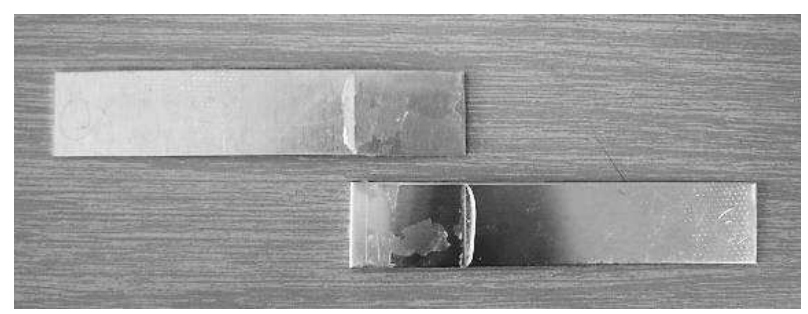

Fig. 5 Example of adhesion failure (AF)

First, the influence of the granulation of abrasive paper on the strength of the adhesive joint was examined. It was expected that the shear strength would increase with increasing surface roughness [26]. It can be seen that for method A, the strength of the adhesive joint increases from to P220 abrasive papers, and then rapidly degreases. The highest value of the shear strength for method B was obtained for P120 abrasive paper. In this case the trend is unstable - it alternately decreases and increases with the change of the granulation of abrasive paper. Thus, increasing the surface roughness does not always increase the strength of the adhesive joints. Budhe et al. [27] reached similar conclusions. They showed that the strength of the adhesive joints depends on the type of bonded material. The moderate value of the surface roughness results in a diffusion of moisture, which contributes to the durability of the adhesive joint [28]. Thus, the surface roughening could be applied to certain optimal values, characteristic for a type of material. In [29] it was stated that the $1.7-3.1 \mu \mathrm{m} \mathrm{Ra}$ and $36.5-44.6 \mu \mathrm{m} \mathrm{Rm}$ provide the highest shear strength of the adhesive joint.

Comparing the strength results for degreasing, the higher strength for method B was obtained for P120, P400 and P600 abrasive papers. For method A the shear strength obtained using P180 and P220. In most cases, degreasing increased the strength of the adhesive joint [30,31].

The strength of the adhesive joint is the resultant of many factors, including technological factors. Due to the specificity of the adhesive technology, in many cases the strength cannot be clearly predicted, therefore experimental tests are carried out. The results of the research on the influence of machining operations - machining with abrasive tools on the surface free energy value of hot-dip zinc coated sheets are presented in [21]. On their basis, it can be concluded that the highest value of the surface free energy of hot-dip galvanized sheets was obtained after abrasive treatment with the P320 $\left(50.0 \mathrm{~mJ} / \mathrm{m}^{2}\right)$ and P120 $\left(49.0 \mathrm{~mJ} / \mathrm{m}^{2}\right)$ heaped tool. The highest value of the polar component $\gamma_{\mathrm{sp}}\left(16.8 \mathrm{~mJ} / \mathrm{m}^{2}\right)$ is also associated with the treatment with P320 sandpaper. The lowest value of surface free energy was obtained after treatment with a P500 abrasive bulk tool $\left(45.7 \mathrm{~mJ} / \mathrm{m}^{2}\right)$.

It has been noticed that greater grain size contributes (under the assumed conditions) to a greater value of the surface free energy and it can be assumed that this will allow for greater strength of the adhesive joints of the analysed sheets. In this study, the preliminary assumptions were confirmed, inferred on the basis of the results published in other studies on the value of surface free energy, because the mechanical treatment of galvanized sheets with the use of sandpaper of the highest grain (P120) allowed to obtain the highest strength among the studied cases, and galvanized sheets with the use of sandpaper of the smallest grain (P500) contributed to obtaining the lowest strength. Based on the result (Fig. 2), it can be seen that for lower grain sizes the application of degreasing after roughing with abrasive paper is more advantageous. Degreasing does not increase the strength in the case of papers with lower granulation (excluding the variant of the abrasive paper with the highest grain size). The use of abrasive paper with a lower granulation and leaving the products on the treated surface weakens the adhesive bonds more than the use of abrasive papers with a higher granulation. This may be due to the 
treatment products partially remaining in the unevenness. This issue will be developed in further research.

The surface roughness was tested only for samples without the use of degreasing agent. It has been shown that the increase in the granulation of abrasive paper causes a decrease in the surface roughness parameters (except for P400 for the Ra parameter and P120 for the Rt parameter).

\section{Conclusion}

The following conclusions were made on the basis of the conducted research:

- The examined factors influence the strength of the adhesive joint. The method $(\mathrm{M})$ has the highest influence on the strength, followed by the granulation of the abrasive paper $(\mathrm{P})$. The lowest influence has the interaction $\mathrm{P} \times \mathrm{M}$.

- The highest shear strength was noticed for method B using P120 abrasive paper and the lowest value of the shear strength was observed for method A using P600 abrasive paper.

- Preparation of the adherends surafce using a degreasing increases the shear strength of single-lap adhesive joints made of hot dip galvanized steel sheet.

- Machining with abrasive papers of higher granularity contributes to the increase of the strength properties of adhesive joints.

\section{Acknowledgement}

The article was made under support grant project KEGA 011ŽU-4/2020 Implementation of online education in the field of bearing technology with an emphasis on the educational process for improving the skills and flexibility of engineering technology students.

\section{References}

[1] GRANT L.D.R., ADAMS R.D., DA SILVA L.F.M. (2009) Experimental and numerical analysis of single-lap joints for the automotive industry. International Journal of Adhesion and Adhesives, 29, 405-413.

[2] FANECO T.M.S., CAMPILHO R.D.S.G., SILVA F.J.G., LOPES R.M. (2017) Strength and fracture characterization of a novel polyurethane adhesive for the automotive industry. Journal of Testing and Evaluation, 45, 398-407.

[3] HE X. (2011) A review of finite element analysis of adhesively bonded joints. International Journal of Adhesion and Adhesives, 31, 248-264.
[4] DA SILVA L.F.M., DAS NEVES P.J.C., ADAMS R.D., WANG A., SPELT J.K. (2009) Analytical models of adhesively bonded joints Part II: Comparative study. International Journal of Adhesion and Adhesives, 29, 331-341.

[5] SUN S., LI M., LIU A. (2013) A review on mechanical properties of pressure sensitive adhesives. International Journal of Adhesion and Adhesives, 41, 98-106.

[6] XU W., WEI Y.G. (2012) Strength and interface failure mechanism of adhesive joints. International Journal of Adhesion and Adhesives, 34, 80-92.

[7] KOLÁŘ V., MÜLLER M., TICHÝ M., RUDAWSKA A., HROMASOVÁ M. (2019) Influence of preformed adherent angle and reinforcing glass fibre on tensile strength of hybrid adhesive bond. Manufacturing Technology 19 (5), 786-791

[8] PROLONGO S.G., URENA A. (2009) Effect of surface pre-treatment on the adhesive strength of epoxy-aluminium joints. International Journal of Adhesion and Adhesives, 29, 23-51.

[9] ROTELLA G., ALFANO M., SCHIEFER T., JANSEN I. (2016) Evaluation of mechanical and laser surface pre-treatments on the strength of adhesive bonded steel joints for automotive industry. Journal of Adhesion Science and Technology, 30, 747-758.

[10] ZIELECKI W., PAWLUS P., PERLOWSKI R., DZIERWA A. (2013) Surface topography effect on strength of lap adhesive joints after mechanical pretreatment. Archives of Civil and Mechanical Engineering, 13, 175-185.

[11] SPAGGIARI A., DRAGONI E. (2013) Effect of mechanical surface treatment on the static strength of adhesive lap joints. The Journal of $A d$ besion, 89, 677-696.

[12] KUBIT A., CIECIŃSKA B., DROZD K (2015) The influence of lap size on shear strength of adhesive joints. Advances in Science and Technology Research Journal, 9, 104-108.

[13] RUDAWSKA A. (2014) Selected aspects of the effect of mechanical treatment on surface roughness and adhesive joint strength of steel sheets. International Journal of Adhesion and Adhesives, 50, 235-243.

[14] LAOUAR L., HAMADACHE H., SAAD S., BOUCHELAGHEM, A., MEKHILEF S. (2008) Mechanical surface treatment of steel Optimization parameters of regime. Physics Procedia, 2, 1213-1221.

[15] RUDAWSKA A, STANČEKOVÁ D., BRZECZEK. (2016) The visual method in quality assessment of single-lap adhesive joints. 
Advances in Science and Technology Research Journal, 10, 109-118.

[16] DRAGONI E., GOGLIO L. (2013) Adhesive stresses in axially-loaded tubular bonded joints -Part I:Critical review and finite element assessment of published models. International Journal of Adhesion and Adhesives, 47, 35-45.

[17] MÜLLER M., HRABĚ P., CHOTĚBORSKÝ R., HERÁK D. (2006) Evaluation of factors influencing adhesive bond strength. Research in Agricultural Engineering, 52, 30-37.

[18] GULTEKIN K., AKPINAR S., OZEL A. (2014) The effect of the adherend width on the strengthof adhesively bonded single-lap joint: Experimental and numerical analysis. Composites Part B: Engineering, 60, 736-745.

[19] GUZANOVA A., BREZINOVA J., DRAGNOVSKA D., JAS F. (2014) A study of the effect of surface pre-treatment on the adhesion of coatings. Journal of Adhesion Science and Technology, 28, 1754-1771.

[20] DYL T. (2014) Analysis of the possibility of applying of alloy and composite coatings after plastic working in shipbuilding. Advances in $\mathrm{Ma}$ terials Science, 14, 82-91.

[21] RUDAWSKA A., KUCZMASZEWSKI J. (2005) Bonding of galvanizing steel sheets. University Publishing, Lublin, Poland, ISBN 8389246-43-0 (in polish).

[22] SHANG X., MARQUES E.A.S., MACHADO J.J.M., CARBAS R.J.C., JIANG D., DA SILVA L.F.M. (2019) Review on techniques to improve the strength of adhesive joints with composite adherends. Composites Part B: Engineering 177

[23] BORSELLINO C., DI BELLA G., RUISI V.F. (2009) Adhesive joining of aluminium AA6082: The effects of resin and surface treatment. International Journal of Adhesion and Adhesives, 29, 36-44.

[24] DA SILVA L.F.M., CARBAS R.J.C., CRITCHLOW G.W., FIGUEIREDO M.A.V.,
BROWN, K. (2009) Effect of material, geometry, surface treatment and environment on the shear strength of single lap joints. International Journal of Adhesion and Adhesives, 29, 621-632.

[25] GIESTEIRA F.A.G., MARQUES A.S., CARBAS R.J.C., DA SILVA L.F.M. (2017) Prediction of Joint Strength and Effect of the Surface Treatment on the Single Overlap Adhesive Joints. U. Porto Journal of Engineering, 3, 1-16.

[26] SALEEMA N., SARKAR D.K., PAYNTER R.W., GALLANT D., ESKANDARIAN M. (2012) A simple surface treatment and characterization of AA 6061 aluminum alloy surface for adhesive bonding applications. Journal of $A p$ plied Surface Science, 261, 742-748.

[27] BUDHE S., GHUMATKAR A., BIRAJDAR N., BANEA M. D. (2015) Effect of surface roughness using different adherend materials on the adhesive bond strength. Applied Adhesion Science 20

[28] LI J., LI Y., HUANG M., XIANG Y., BI R., TU CH., WANG B. (2019) Surface Treatment for Improving Durability of AluminumLithium, Adhesive-Bonded Joints under HotHumid Exposure. Coatings, 9, 346.

[29] HIRULKARA N.S, JAISWALB P.R, ALESSANDROC P., REIS P. (2018) Influence of Mechanical surface treatment on the strength of mixed adhesive joint. Materials Today: Proceedings, 5, 18776-18788.

[30] MÜLLER M., RUDAWSKA A., TICHÝ M., KOLÁř V., HROMASOVÁ M. (2020) Research on wear resistance of polymeric composite materials based on microparticles from tyre recyclation process. Manufacturing Technology 20 (2), 223-228

[31] RUDAWSKA A., NALEPA J., MÜLLER M. (2017) The effect of degreasing on adhesive joint strength. Advances in Science and Technology Research Journal, 11, 75-81. 